\title{
Apixaban Discontinuation for Invasive Or major Surgical procedures (ADIOS): A prospective cohort study.
}

\author{
Geno J. Merli \\ Thomas Jefferson University \\ Walter K. Kraft \\ Thomas Jefferson University \\ Luis H. Eraso \\ Thomas Jefferson University \\ Taki Galanis \\ Thomas Jefferson University

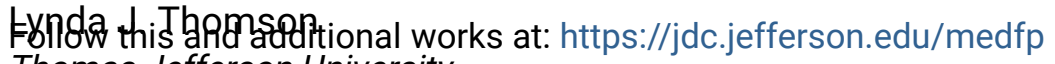 \\ Thomas Jefferson University \\ Part of the Pharmacy and Pharmaceutical Sciences Commons, and the Surgery Commons \\ Let us know how access to this document benefits you
}

\section{Recommended Citation}

Merli, Geno J.; Kraft, Walter K.; Eraso, Luis H.; Galanis, Taki; Thomson, Lynda J.; Ouma, Geoffrey O.; Viscusi, Eugene; Gong, Jerald Z.; and Lam, Edwin, "Apixaban Discontinuation for Invasive Or major Surgical procedures (ADIOS): A prospective cohort study." (2021). Department of Medicine Faculty Papers. Paper 315. https://jdc.jefferson.edu/medfp/315

This Article is brought to you for free and open access by the Jefferson Digital Commons. The Jefferson Digital Commons is a service of Thomas Jefferson University's Center for Teaching and Learning (CTL). The Commons is a showcase for Jefferson books and journals, peer-reviewed scholarly publications, unique historical collections from the University archives, and teaching tools. The Jefferson Digital Commons allows researchers and interested readers anywhere in the world to learn about and keep up to date with Jefferson scholarship. This article has been accepted for inclusion in Department of Medicine Faculty Papers by an authorized administrator of the Jefferson Digital Commons. For more information, please contact: JeffersonDigitalCommons@jefferson.edu. 


\section{Authors}

Geno J. Merli, Walter K. Kraft, Luis H. Eraso, Taki Galanis, Lynda J. Thomson, Geoffrey O. Ouma, Eugene Viscusi, Jerald Z. Gong, and Edwin Lam 


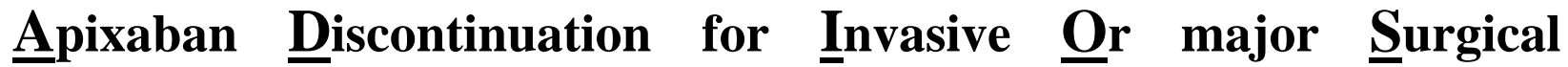 procedures (ADIOS): A prospective cohort study.}

Geno J. Merli ${ }^{1,2}$, Walter K. Kraft ${ }^{3,1,2}$, Luis H. Eraso ${ }^{1,2}$, Taki Galanis ${ }^{1,2}$, Lynda J. Thomson ${ }^{4}$, Geoffrey O. Ouma ${ }^{7}$, Eugene Viscusi ${ }^{6}$, Jerald Z. Gong ${ }^{5}$, Edwin Lam ${ }^{3}$

Departments of Medicine ${ }^{1}$, Surgery ${ }^{2}$, Pharmacology and Experimental Therapeutics ${ }^{3}$, Pharmacy $^{4}$, Pathology ${ }^{5}$, and Anesthesiology ${ }^{6}$, Thomas Jefferson University, Philadelphia, PA

Department of Cardiovascular Medicine, Section of Vascular Medicine, Heart Vascular and Thoracic Institute ${ }^{7}$, Cleveland Clinic, Cleveland, $\mathrm{OH}$

\section{Corresponding Author}

Geno Merli, MD, MACP

111 S. $10^{\text {th }} \mathrm{St}$, 6270 Gibbon Building

Philadelphia, PA 19107

215 503-1022

The current affiliation of Dr. Lam is Clinical Pharmacokinetics Research Unit, Pharmacy Department, National Institutes of Health, Bethesda, MD, USA

\section{Acknowledgment}

We thank Douglas Stickle, PhD for apixaban analytic measurement, Scott Keith, PhD for power analysis and Suzanne Adams, RN, Daniel Schwegler, RN, BSN and Melissa McCurdy for data management

Key Words

Peri-operative

Apixaban

Anticoagulation

pharmacokinetics

Abbreviation: $\mathrm{DOAC}=$ direct oral anticoagulant

Word count (excluding abstract): 2664

Abstract word count: 236

Figures: 5

Tables: 2

Supplemental Material: 3 figures and 2 tables 


\begin{abstract}
Background

Apixaban pharmacokinetic properties and some clinical reports suggest cessation 48 hours prior to surgery is safe, but this has not been demonstrated in a naturalistic setting. We sought to measure the residual apixaban exposure in patients who had apixaban held as part of standard of care perioperative management.

Methods

This was a prospective, observational study of patients in whom apixaban plasma concentration and anti-Xa activity were measured while at steady state apixaban dosing and again immediately prior to surgery. Clinical management of cessation and resumption of apixaban was at the discretion of the treating physician.

Results

One hundred and eleven patients provided paired blood samples. Ninety four percent (104/111) patients had measured apixaban concentrations of $\leq 30 \mathrm{ng} / \mathrm{mL}$. Only one patient had a value $>50$ $\mathrm{ng} / \mathrm{mL}$. The median time between the self-reported last dose and pre-surgery blood sampling was 76 hours (range $32-158$ ) for those who achieved concentrations $\leq 30 \mathrm{ng} / \mathrm{mL}$ and 59 hours (range $49-86$ ) for those $>30 \mathrm{ng} / \mathrm{mL}$. Measured anti-Xa activity correlated well with apixaban exposure. Clinically significant non-major bleeding was reported in one patient at 1-week post-surgery. There was one venous thromboembolic event and one stroke in the peri-operative period.

\section{Conclusion}

In a naturalistic setting with a heterogeneous patient population, apixaban discontinuation for at least 48 hours before a procedure resulted in a clinically insignificant degree of anticoagulation prior to a surgical procedure. (NCT02935751)
\end{abstract}




\section{Introduction}

Apixaban is a direct oral anticoagulant (DOAC) approved for multiple indications. The need to interrupt anticoagulation in the perioperative period is common. Approaches for the discontinuation of DOACs are based upon the pharmacokinetic parameters of the drug in the context of individual patient and procedural characteristics. The US apixaban product insert specifies the last dose be held at least 24 hour before a low bleeding risk procedure and at least 48 hours prior to elective surgery or invasive procedures with a moderate or higher risk bleeding.(1) This is based upon a population half-life of $\sim 12$ hours, only modest decreases in drug clearance with hepatic or renal dysfunction, and linearity of pharmacokinetics across clinically used doses. However, population pharmacokinetic methods have noted moderate between-patient variation based upon known parameters such as age, size, and renal function, with unexplained covariates accounting for $\sim 30 \%$ of variation.(2) The additive effects of multiple patient characteristics may impact apixaban clearance. Treating physicians may not be aware of all clinical factors that could impact apixaban clearance. In addition, the clearance of apixaban declines after orthopedic surgery by $\sim 25 \%$, which returns to baseline by post op day 4.(3) All of these factors highlight the potential that in actual use, expected apixaban exposures may diverge from model predicted values. The effectiveness of a peri-operative apixaban cessation approach in the setting of actual practice with a heterogonous patient population was studied by Douketis in the PAUSE trial.(4) We hypothesized that discontinuation of apixaban for at least 48 hours prior to surgical procedures in a naturalistic observational setting would result in a clinically insignificant residual anticoagulation as defined by apixaban plasma concentration $<30 \mathrm{ng} / \mathrm{mL}$. 


\section{Methods}

This was a single site, prospective, observational study of patients receiving standard of care perioperative management of apixaban anticoagulation (NCT02935751). The study population was patients who were already receiving treatment with apixaban for non-valvular atrial fibrillation or venous thromboembolism and who required an elective major surgical or invasive procedure. All patients had a plasma apixaban and anti-Xa level drawn at steady state at the preadmission clinical visit and on the morning of surgery. The steady state concentration collection was taken at the pre-admission visit. The time of collection relative to last dose of apixaban was not fixed. Apixaban was stopped and restarted at the discretion of the treating physician, and there was no protocol-specified or suggested interval for cessation. Institutional guidance suggested cessation 48 hours prior to a surgical procedure. Adverse events and bleeding events were collected to 30 days post procedure. Major bleeding was defined as fatal or in a critical organ, non- surgical bleeding with a $2 \mathrm{~g} / \mathrm{dL}$ decrease in hemoglobin or requiring transfusion of 2 units or more of blood, surgical site bleeding that required surgical intervention or resulted in hemarthrosis within 30 days of cessation of therapy. Arterial thromboembolic events, venous thromboembolism and death by any cause were recorded if they occurred within 30 days of the last dose of apixaban. (Figure 1) The Thomas Jefferson University Institutional Review Board approved the study, and all patients were provided written informed consent.

Consecutive patients were assessed for study participation eligibility in the pre-admission testing center. Inclusion criteria included adults greater than 18 years of age; on long term anticoagulation with apixaban (5 $\mathrm{mg}$ or $2.5 \mathrm{mg}$ twice daily) for treatment of non-valvular atrial fibrillation or venous thromboembolism; scheduled for elective surgery or invasive procedure which required anticoagulation interruption; and able to adhere to apixaban interruption protocol at the time of 
enrollment. Patients were excluded if they had more than one procedure planned within 30 days; creatinine clearance less than $30 \mathrm{~mL} / \mathrm{min}$; cognitive impairment or major psychiatric illness; previous study participation or participation in another clinical trial. Patients with a creatinine clearance $<30 \mathrm{~mL} / \mathrm{min}$ were excluded at the time of this study base on our hospital's guidelines for the use of direct oral anticoagulants with creatinine clearance below this value at the time the protocol was written. VTE prophylaxis is not routinely provided post-operatively pending therapeutic DOAC re-initiation. A log of doses taken by the patient for the 7 days prior to surgery was recorded. Before the procedure, patients were categorized as having a high or low bleeding risk procedure according to a pre-specified classification listed in Supplemental Table 1. Patients were followed daily during their hospitalization to assess resumption of apixaban and document hemorrhagic or thrombotic events. Patients received phone contact at day 7 and 30 post discharge to assess bleeding, thrombotic events or hospital readmission.

\section{Statistical methods}

The primary outcome of the ADIOS study was the estimation of the proportion of patients who achieved a plasma apixaban concentration of $\leq 30 \mathrm{ng} / \mathrm{mL}$ following at least 48 hours of discontinuation prior to surgery or invasive procedure. This threshold is based upon International Society for Thrombosis and Hemostasis recommendations for reversal,(5) expert opinion as clinically important,(6-8) and represents a value below that seen after 3-4 half-lives based upon published pharmacokinetic parameters in patient populations.(2) The secondary outcome was the incidence of postoperative arterial or venous thromboembolic events, major bleeding and clinically significant non-major bleeding complications. Based on similar studies performed $(9,10)$ in which $86 \%$ of patients had a plasma level at or below $30 \mathrm{ng} / \mathrm{mL}$ at least 48 hours after discontinuation, we hypothesized that the proportion in the population was likely to be between $80 \%$ and $95 \%$ for 
apixaban. One hundred thirty patients were chosen as having a reasonably narrow ClopperPearson(11) exact 95\% confidence interval (CI) at the lowest anticipated observed proportion (CI width of 0.15 if proportion is 0.80 ) and high confidence in the location of the population proportion if nearly all or all patients reached the threshold of $<30 \mathrm{ng} / \mathrm{mL}$ (CI widths of 0.08 and 0.03 for proportions of 0.95 and 1.00, respectively). (Supplemental Table 2) All study variables were summarized by means and standard deviations or, if substantially skewed, by medians with the first and third quartiles using $\mathrm{R}$ version 4.0.2. Plots were generated using the R package ggplot2. Pearson's correlation coefficients were used to estimate correlation between the apixaban concentration and anti-Xa apixaban activity. Two-sided significance was set at $\mathrm{a}=0.05$.

\section{Analytic procedure}

Plasma concentrations of apixaban were determined by liquid chromatography-tandem mass spectrometry using an AB Sciex API 3200MD.(12) Commercial calibrators (Hyphen Biomed) were used, along with d4-rivaroxaban (Santa Cruz Biotechnology, Santa Cruz, CA) as an internal standard. The calibration curve was linear over the range 0-600 $\mathrm{ng} / \mathrm{mL}$. Between-run precisions were $8.4 \%$ (at $30 \mathrm{ng} / \mathrm{mL}$ ) and $4.7 \%$ (at $200 \mathrm{ng} / \mathrm{mL}$ ). The lower limit of quantitation (LLOQ) was $4 \mathrm{ng} / \mathrm{mL}$. No analytical interferences or ion suppression effects have been observed in precedent LC-MS/MS assays.(13) Anti-Xa was performed on ACL-TOP500 using Biophen Heparin LRT and Biophen Apixaban calibrator from Aniara Diagnostica (West Chester, OH). Two level controls ( $\sim 72$ and $\sim 275 \mathrm{ng} / \mathrm{mL}$, Biophen Apixaban control) were performed on each run.

\section{Results:}

\section{Study Population}

The enrollment period for the ADIOS trial lasted 18 months, from December 2016 through July 
2018. Of the 130 patients enrolled in the trial, 111 paired blood samples were available for the primary outcome of change in plasma apixaban concentration. (Figure 2) There were 19 patients who were excluded due to missing variables, including missing apixaban concentrations at preadmission testing, day of surgery or both. The primary reason for a missed blood draw was last minute cancellation of the scheduled surgery ( 6 patients), and 5 patients were missed because the operating room schedule in the electronic medical record was inaccurate and patients were taken for surgery earlier than anticipated. Two of the patients did not have a sample drawn because they had difficult vein access, and the study coordinator could not get the sample after three attempts. Patient apixaban dose was available for all 111 patients with paired blood samples. Patient demographics and disposition are listed in Table 1. The proportion of patients achieving apixaban concentrations of less than or equal to $30 \mathrm{ng} / \mathrm{mL}$ was $93.7 \%$. (Figure 3)

The median time between the self-reported last dose and day of surgery blood sampling was 75.5 hours (32.4 - 157.8 hours) for those who achieved concentrations less than or equal to $30 \mathrm{ng} / \mathrm{mL}$ and 59.3 hours ( $49.4-86.4$ hours) for those greater than $30 \mathrm{ng} / \mathrm{mL}$. Figures 4 and 5 display the proportion of patients achieving target apixaban concentrations based on duration of apixaban discontinuation and dose of apixaban, respectively. All seven patients who did not achieve target plasma apixaban levels were on a maintenance dose of $5 \mathrm{mg}$ twice daily. Pre-admission and preoperative concentrations of apixaban, and anti-Xa, and clinical characteristics of patients who did and did not achieve target plasma apixaban levels are presented in Table 2.

Pharmacokinetic endpoint data was available for 111 of the 130 total patient population. A total of eleven patients were lost to follow up with nine and two patients at one week and 4 week followups, respectively. Clinically significant non-major bleeding was reported in one patient at 1-week 
post-surgery follow-up. There were two reported venous thromboembolic events during the study and follow-up periods. Of these two, one had restart of apixaban at 50 hours and another at 158 hours post surgery. There were 10 major adverse cardiac events, 2 strokes and 5 arrhythmias. One patient reported both stroke and arrhythmia during the initial hospitalization. Clinical endpoint data is summarized in Table 3. A Welch two sample t-test was used to compare the binary distribution between patients that had events to those that did not have events revealed that there was no significant correlation between these events and mean plasma apixaban levels with a mean difference of $0.25 \mathrm{ng} / \mathrm{mL}$ (95\% CI: $-14.6,15.1, \mathrm{p}=0.97)$ between both groups.

\section{Discussion:}

A high proportion $(100 \%)$ of patients achieved target apixaban concentrations $(\leq 30 \mathrm{ng} / \mathrm{mL})$ following at least 48-hours of discontinuation prior to surgery, and a greater proportion of patients (>90\%) achieved target apixaban levels after discontinuation for $>60$ hours. Patients who did not achieve target plasma apixaban levels tended to be older and have poorer creatinine clearance, with a mean $( \pm$ standard deviation) age of $71.4( \pm 10.7)$ years and median (range) creatinine clearance of $44(13-97) \mathrm{mL} / \mathrm{min}$. The median concentration observed for these patients at the pre-admission blood sampling was $330(171-573) \mathrm{ng} / \mathrm{mL}$. As home dosing the morning of collection at steady state will have varied, these concentrations are considered random and do not necessarily represent maximal (Cmax) or average steady state concentration for any one individual. For comparison, predicted Cmax for patients receiving $5 \mathrm{mg}$ BID for stroke prevention in non-valvular atrial fibrillation is $171 \mathrm{ng} / \mathrm{mL}(95 \%$ CI 91, 321).(2) Our results suggest that the recommended 48-hour discontinuation period is adequate for most individuals to achieve adequate resolution of anticoagulation. The effect of these patient-specific factors was almost entirely absent 
at 60 hours, suggesting that a discontinuation period longer than 3 days will not reduce anticoagulation associated bleeding events in the peri-operative period. All 7 of the patients who did not achieve the target plasma apixaban level of $\leq 30 \mathrm{ng} / \mathrm{mL}$ were on a daily dose of $5 \mathrm{mg}$ twice daily, though none were taking concomitant inhibitors of CYP450 enzymes or p-glycoprotein. Dose is a primary driver of systemic exposure. Dose, in addition to patient characteristics, concomitant medications, and perceived bleeding risk, will play a role in a physician's assessment of individualizing the appropriate discontinuation time.

Anti-Xa levels were highly correlated with plasma apixaban, especially at higher prediscontinuation concentrations. Validity of the analytic method was demonstrated by significant correlation $(\mathrm{p}<0.001)$ between anti-Xa activity and plasma apixaban concentration measured on the visit prior to discontinuation and on the day of surgery. (Supplemental Figure 1) This is consistent with a known linearity between concentration and anti-Xa over a range of therapeutic doses.(2) Further external validation of our methods was indicated by an apparent positive trend between apixaban concentration and age, and a negative trend between apixaban concentration, weight, and creatinine clearance measured at steady state (first blood draw). (Supplemental Figures 2 and 3)

No significant safety issues were observed related to the discontinuation of apixaban. Of the 7 patients who had a day of surgery apixaban concentration of $>30 \mathrm{ng} / \mathrm{ml}$, only two experienced a peri-operative adverse events neither of which were bleeding. Of the remaining 104 patients, the rates of major adverse cardiac events, arterial thrombosis, recurrent venous thromboembolism, and death were low, most of which were attributed to underlying disease rather than discontinuation 
of apixaban. The primary endpoint of this observational study was pharmacokinetic and the study was not powered to make inferences about the efficacy and safety of the apixaban discontinuation approach recommended in the product insert. While the numbers were too small to perform a robust statistical analysis, the small rates of cardiac and thromboembolic events suggest the safety of the prescribed discontinuation period were reassuring. One of the major limitations of this trial is that it was an observational study assessing provider-directed discontinuation rather than a standardized protocol, which led to a wide range of pre-surgery discontinuation windows. Another limitation was that the exact time of last dose for both visits was patient reported and subject to recall bias and the variability associated with patient self-reporting in a naturalistic setting. This lack of exact dose time and limited number of samples prevented the use of population pharmacokinetic approaches that could have otherwise been used to identify covariates associated with pharmacokinetic variation. Lastly, the reported cut off of $30 \mathrm{ng} / \mathrm{mL}$ was chosen as a reasonable surrogate of a safe level for an invasive procedure. This has not been defined in large studies with clinical endpoints. Despite the varied patient population, only one patient had an apixaban concentration $>50 \mathrm{ng} / \mathrm{ml}$. For comparison, $50 \mathrm{ng} / \mathrm{ml}$ is the model predicted minimum apixaban concentration for patients prescribed apixaban $2.5 \mathrm{mg}$ BID for the prevention of venothromboembolic events in hip or knee replacement surgery (95\% CI 23,109).(3) While in the PAUSE trial with a DOAC 48 hour prior to surgery discontinuation time, $90.5 \%$ of the apixaban group achieved drug plasma level of less than $50 \mathrm{ng} / \mathrm{ml}$. The major bleeding incidence was $2.96 \%$ (95\% CI, 0\%-4.68\%) in the apixaban group undergoing high bleeding risk surgery. (4) In patients with serious bleeding, only a drug concentration $>50 \mathrm{ng} / \mathrm{mL}$ is likely sufficiently high to warrant antidote administration, whereas in those requiring an urgent intervention associated with a high risk of bleeding, antidote administration is advocated if the drug concentration exceeds $30 \mathrm{ng} / \mathrm{mL}$. 
$(5,8)$ In the current study, even those with $>30 \mathrm{ng} / \mathrm{ml}$ of apixaban had an order of magnitude reduction in both apixaban and anti-Xa activity on the morning of surgery compared to steady state concentration. The number of patients prescribed $2.5 \mathrm{mg}$ was low. This is not an impact for those prescribed this for prophylaxis, as pre-surgery concentrations will be expected to be lower than those prescribed $5 \mathrm{mg}$. While formal pharmacokinetic modeling was not done on such a small set of patients, even those taking the labeled dose reduction due to at least two of 1) age greater than or equal to 80 years, 2) body weight less than or equal to $60 \mathrm{~kg}$, or 3) serum creatinine greater than or equal to $1.5 \mathrm{mg}$ would be expected to have similar or lower apixaban pharmacokinetic exposure than those prescribed $5 \mathrm{mg}$. In totality, the findings of this study suggest no role for anti-Xa assays in the routine management of cessation of apixaban for elective surgical procedures. A strength of this study is the generalizability of the results to patients assessed in clinical practice, as a high proportion of screened patients were enrolled (83\%). Another strength is the clinical applicability of the apixaban regimen management we assessed, as most patients adhered to a physician directed perioperative apixaban therapy interruption (95\%) and resumption (93\%) management protocol.

\section{Conclusion}

A large proportion of patients (93.7\%; 95\% CI: 88-97\%) achieved plasma apixaban concentrations of $\leq 30 \mathrm{ng} / \mathrm{mL}$ following at least 48 hours of discontinuation. A greater proportion ( $>90 \%)$ of patients achieved below $30 \mathrm{ng} / \mathrm{mL}$ when apixaban was discontinued for $>60$ hours. The clinical evidence here supports current pharmacokinetic discontinuation strategies based on patient factors and apixaban half-life. 


\section{Funding}

This research was funded by an investigator-initiated research award from Bristol-Myers Squibb and Pfizer, as part of the American Thrombosis Investigator Initiated Research Program (ARISTAUSA). Study design, research conduct, analysis, and manuscript preparation was conducted by the Thomas Jefferson University investigators, who had final editorial control over the published content. Edwin Lam was supported by a National Institutes of Health institutional training grant T32GM008562-24.

\section{Disclosures}

Dr. Galanis has served as a speaker for Jansson. No other authors have relevant disclosures. 


\section{References}

(1) Eliquis Product Insert, BMS, Princeton NJ and Pfizer, NY, NY. 11/2019.

(2) Byon W, Garonzik S, Boyd RA, Frost CE. Apixaban: A Clinical Pharmacokinetic and Pharmacodynamic Review. Clin Pharmacokinet 2019 Oct;58(10):1265-1279.

(3) Leil TA, Frost C, Wang X, Pfister M, LaCreta F. Model-based exposure-response analysis of apixaban to quantify bleeding risk in special populations of subjects undergoing orthopedic surgery. CPT Pharmacometrics Syst Pharmacol 2014 Sep 17;3:e136.

(4) Douketis JD, Spyropoulos AC, Duncan J, Carrier M, Le Gal G, Tafur AJ, et al. Perioperative Management of Patients With Atrial Fibrillation Receiving a Direct Oral Anticoagulant. JAMA Intern Med 2019 Nov 1;179(11):1469-1478.

(5) Levy JH, Ageno W, Chan NC, Crowther M, Verhamme P, Weitz JI, et al. When and how to use antidotes for the reversal of direct oral anticoagulants: guidance from the SSC of the ISTH. J Thromb Haemost 2016 Mar;14(3):623-627.

(6) Godier A, Dincq AS, Martin AC, Radu A, Leblanc I, Antona M, et al. Predictors of preprocedural concentrations of direct oral anticoagulants: a prospective multicentre study. Eur Heart J 2017 Aug 14;38(31):2431-2439.

(7) Godier A, Martin A, Lessire S, Mullier F, Leblanc I, Gouin-Thibault I. Concentrations of direct oral anticoagulants according to guidelines for the periprocedural management of low bleeding risk procedures. Anaesthesia Critical Care \& Pain Medicine 2020 February 2020;39(1):121-122.

(8) Pernod G, Albaladejo P, Godier A, Samama CM, Susen S, Gruel Y, et al. Management of major bleeding complications and emergency surgery in patients on long-term treatment with direct oral anticoagulants, thrombin or factor-Xa inhibitors: proposals of the working group on perioperative haemostasis (GIHP) - March 2013. Arch Cardiovasc Dis 2013 Jun-Jul;106(67):382-393.

(9) Skeppholm M, Al-Aieshy F, Berndtsson M, Al-Khalili F, Ronquist-Nii Y, Soderblom L, et al. Clinical evaluation of laboratory methods to monitor apixaban treatment in patients with atrial fibrillation. Thromb Res 2015 Jul;136(1):148-153.

(10) Godier A, Martin AC, Leblanc I, Mazoyer E, Horellou MH, Ibrahim F, et al. Periprocedural management of dabigatran and rivaroxaban: Duration of anticoagulant discontinuation and drug concentrations. Thromb Res 2015 Oct;136(4):763-768.

(11) Clopper C PE. The use of confidence or fiducial limits illustrated in the case of the binomial. Biometrika. Biometrika 1934;26:404-413. 
(12) Korn W, Paziuk T, Stickle D. Measurement of plasma Apixaban by LC-MS/MS. Clin Chem 2016;62(10S):S214.

(13) Schmitz EM, Boonen K, van den Heuvel DJ, van Dongen JL, Schellings MW, Emmen JM, et al. Determination of dabigatran, rivaroxaban and apixaban by ultra-performance liquid chromatography - tandem mass spectrometry (UPLC-MS/MS) and coagulation assays for therapy monitoring of novel direct oral anticoagulants. J Thromb Haemost 2014 Oct;12(10):1636-1646.

Table 1: Baseline patient characteristics enrolled into the study

\begin{tabular}{|c|c|}
\hline & $\mathrm{N}=130$ \\
\hline Age - years (SD) & $68.6 \pm 11.6$ \\
\hline Sex (Female) & $52 \%$ \\
\hline BMI $\left(\mathrm{kg} / \mathrm{m}^{2}\right)$ & $30[21-52]$ \\
\hline Race & \\
\hline White & $80.6 \%$ \\
\hline Black or African American & $15.4 \%$ \\
\hline Other & $3.1 \%$ \\
\hline Unknown & $0.8 \%$ \\
\hline Apixaban Indication & \\
\hline $\begin{array}{l}\text { Reduction of risk of stroke/TIA or systemic embolism in non-valvular } \\
\text { atrial fibrillation }(n=80)\end{array}$ & $59 \%$ \\
\hline $2.5 \mathrm{mg}$ & $8.8 \%$ \\
\hline $5 m g$ & $79.8 \%$ \\
\hline Unknown & $11.4 \%$ \\
\hline Prevention of recurrent venous thromboembolism $(n=32)$ & $25 \%$ \\
\hline 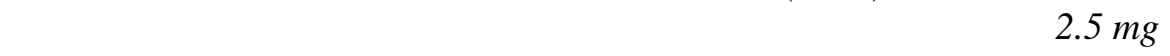 & $18.8 \%$ \\
\hline $5 m g$ & $65.6 \%$ \\
\hline Unknown & $15.6 \%$ \\
\hline Multiple indications* $(n=12)$ & $9 \%$ \\
\hline $2.5 \mathrm{mg}$ & $16.7 \%$ \\
\hline $5 \mathrm{mg}$ & $66.7 \%$ \\
\hline Unknown & $16.7 \%$ \\
\hline Unknown indication $(n=6)$ & $5 \%$ \\
\hline $2.5 \mathrm{mg}$ & $0 \%$ \\
\hline $5 \mathrm{mg}$ & $66.7 \%$ \\
\hline Unknown & $33.3 \%$ \\
\hline
\end{tabular}

*12 patients were taking apixaban for multiple indications: 7 for reduction of risk of stroke in non-valvular atrial fibrillation and prevention of recurrent venous thromboembolism; 1 for reduction of risk of stroke and prevention of recurrent transient ischemic event secondary to atrial fibrillation; 2 for reduction of risk of stroke and prevention of recurrent stroke secondary atrial fibrillation; 1 for prevention of recurrent venous thromboembolism and prevention of recurrent stroke secondary to atrial fibrillation; and 1 for reduction of risk of stroke in atrial fibrillation and prevention of recurrent venous thromboembolism and for prevention of recurrent stroke secondary to atrial fibrillation 
Table 2: Comparison of patient characteristics stratified by observed apixaban concentration on the day of surgery

\begin{tabular}{|c|c|c|}
\hline & $\leq 30 \mathrm{ng} / \mathrm{mL}(\mathrm{n}=104)$ & $>30$ ng/mL $(n=7)$ \\
\hline Age - years (SD) & $68.7 \pm 11.9$ & $71.4 \pm 10.7$ \\
\hline Sex (Female) & $49 \%$ & $50 \%$ \\
\hline $\mathrm{BMI}\left(\mathrm{kg} / \mathrm{m}^{2}\right)$ & $30[21-52)$ & $28[25-38]$ \\
\hline Race & & \\
\hline White & $78.8 \%$ & $100 \%$ \\
\hline Black or African American & $16.3 \%$ & $0 \%$ \\
\hline Other & $3.8 \%$ & $0 \%$ \\
\hline Unknown & $1.0 \%$ & $0 \%$ \\
\hline $\mathrm{CHA}_{2} \mathrm{D}_{2}$-VASc Score & $3.5 \pm 1.7$ & $3.6 \pm 1.5$ \\
\hline $\begin{array}{l}\text { Apixaban Dose } \\
2.5 \mathrm{mg} \text { twice-daily } \\
5 \mathrm{mg} \text { twice-daily }\end{array}$ & $\begin{array}{l}14.4 \% \\
85.6 \%\end{array}$ & $\begin{array}{l}0 \% \\
100 \%\end{array}$ \\
\hline $\begin{array}{l}\text { Pre-admission } \\
\text { Apixaban }(\mathrm{ng} / \mathrm{mL}) \\
\text { Anti-FXa }(\mathrm{IU} / \mathrm{mL}) \\
\end{array}$ & $\begin{array}{l}168.0[13.0-485.0] \\
184.1[0-418.3]\end{array}$ & $\begin{array}{l}330.0[171.0-573.0] \\
408.4[184.0-544.4]\end{array}$ \\
\hline $\begin{array}{l}\text { Pre-surgery } \\
\text { Apixaban }(\mathrm{ng} / \mathrm{mL}) \\
\text { Anti-FXa }(\mathrm{IU} / \mathrm{mL}) \\
\end{array}$ & $\begin{array}{l}0.0[0.0-30.0] \\
8.8[8.8-29.4]\end{array}$ & $\begin{array}{l}38.0[31.0-66.0] \\
42.9[42.9-80.5]\end{array}$ \\
\hline $\begin{array}{l}\text { Procedure Bleeding Risk } \\
\text { Standard } \\
\text { High } \\
\end{array}$ & $\begin{array}{l}51 \% \\
49 \% \\
\end{array}$ & $\begin{array}{l}25 \% \\
75 \%\end{array}$ \\
\hline $\begin{array}{l}\text { Median time following apixaban } \\
\text { cessation to day of surgery blood } \\
\text { draw (hours) }\end{array}$ & $75.5[32.4-157.8]$ & $59.3[49.4-86.4]$ \\
\hline $\begin{array}{l}\text { Median time of apixaban } \\
\text { resumption following the day of } \\
\text { surgery (hours) }\end{array}$ & $60.6[6.8-471.2]$ & $60.6[21.8-152.3]$ \\
\hline Creatinine clearance $(\mathrm{mL} / \mathrm{min})$ & $84[4-188]$ & $44[13-97]$ \\
\hline $\begin{array}{l}\text { Concomitant medications } \\
\text { Diltiazem } \\
\text { Adenosine diphosphate inhibitor } \\
\text { Nonsteroidal anti-inflammatory } \\
\text { Aspirin }\end{array}$ & $\begin{array}{l}12.5 \% \\
4.8 \% \\
11.5 \% \\
18.3 \% \\
\end{array}$ & $\begin{array}{l}25 \% \\
0 \% \\
0 \% \\
37.5 \% \\
\end{array}$ \\
\hline
\end{tabular}


Table 3. Peri-procedural and follow-up complications

\begin{tabular}{|l|c|c|c|}
\hline & $\begin{array}{l}\text { Peri-procedural } \\
\text { complications } \\
\text { n/N (\%) }\end{array}$ & Week Follow up & 30 day Follow up \\
& $18 / 111(16.2 \%)$ & $7 / 111(6.3 \%)$ & $9 / 111(8.1 \%)$ \\
\hline All Stroke & $1(0.9 \%)$ & $1(0.9 \%)$ & $4 /(3.6 \%)$ \\
\hline $\begin{array}{l}\text { Any Major Adverse Cardiac } \\
\text { Event }\end{array}$ & $3(2.7 \%)$ & $0(0 \%)$ & $0(0 \%)$ \\
\hline Arrhythmia & $1(0.9 \%)$ & $1(0.9 \%)$ & $1(0.9 \%)$ \\
\hline Other & $1(0.9 \%)$ & $1(0 \%)$ & $3(2.7 \%)$ \\
\hline Non-major Bleed & $1(0.9 \%)$ & $1(0.9 \%)$ & $1(0.9 \%)$ \\
\hline Thromboembolic Event & $3(2.7 \%)$ & $0(0 \%)$ & $1(0.9 \%)$ \\
\hline Infection & $8(7.2 \%)$ & $4(3.6 \%)$ & $3(2.7 \%)$ \\
\hline Other & & & \\
\hline
\end{tabular}

\section{Figures}

Figure 1: Study design. Timing of cessation of apixaban prior to surgery was at the discretion of the treating physician.

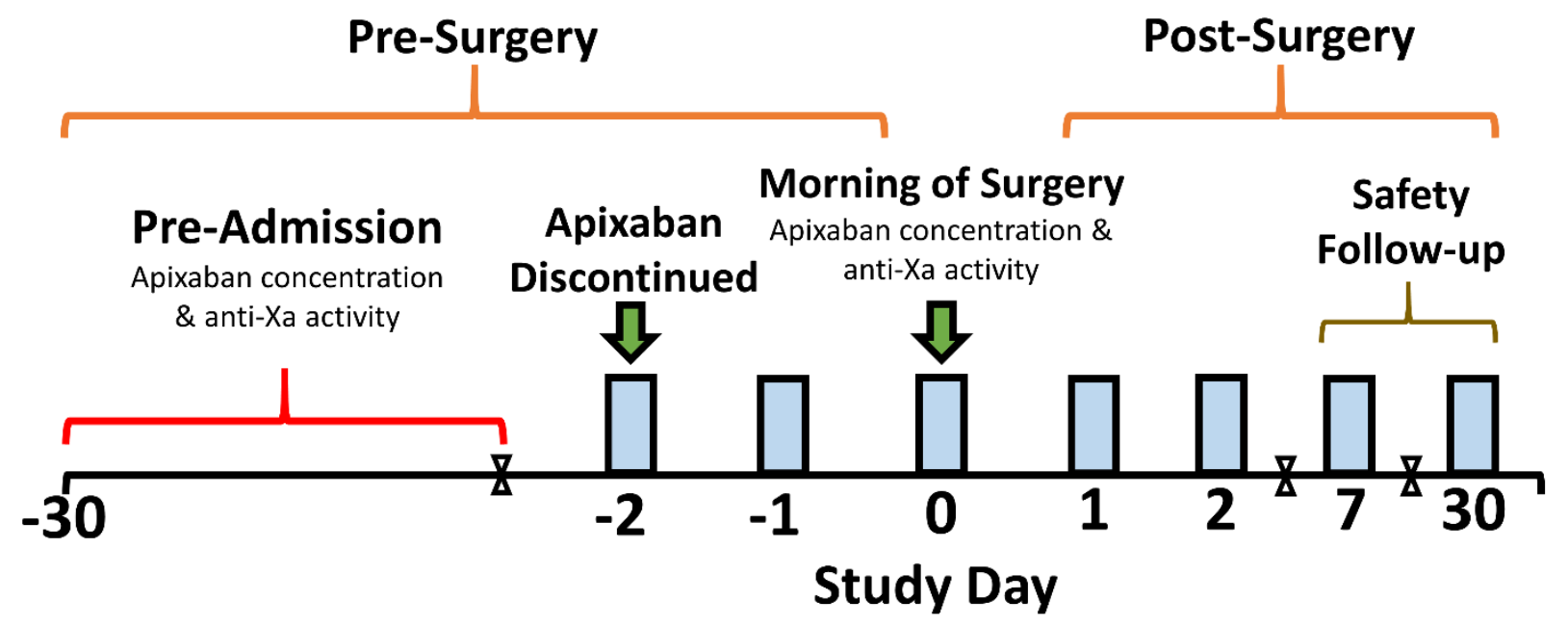


Figure 2: Study subject disposition

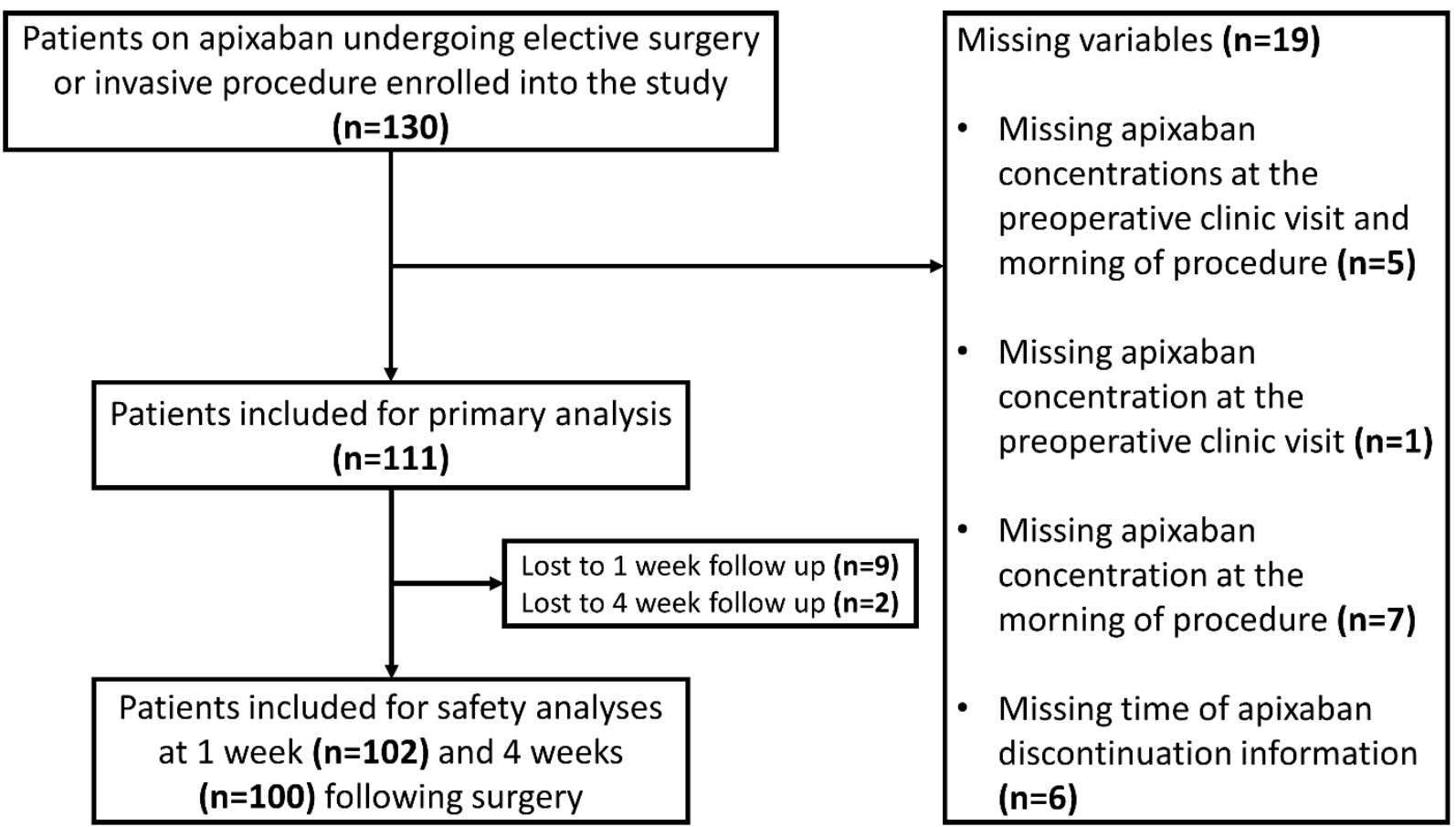

Figure 3: Proportion of patients grouped by apixaban concentrations $>30 \mathrm{ng} / \mathrm{mL}$ and with those achieving $\leq 30 \mathrm{ng} / \mathrm{mL}$, with interquartile ranges.

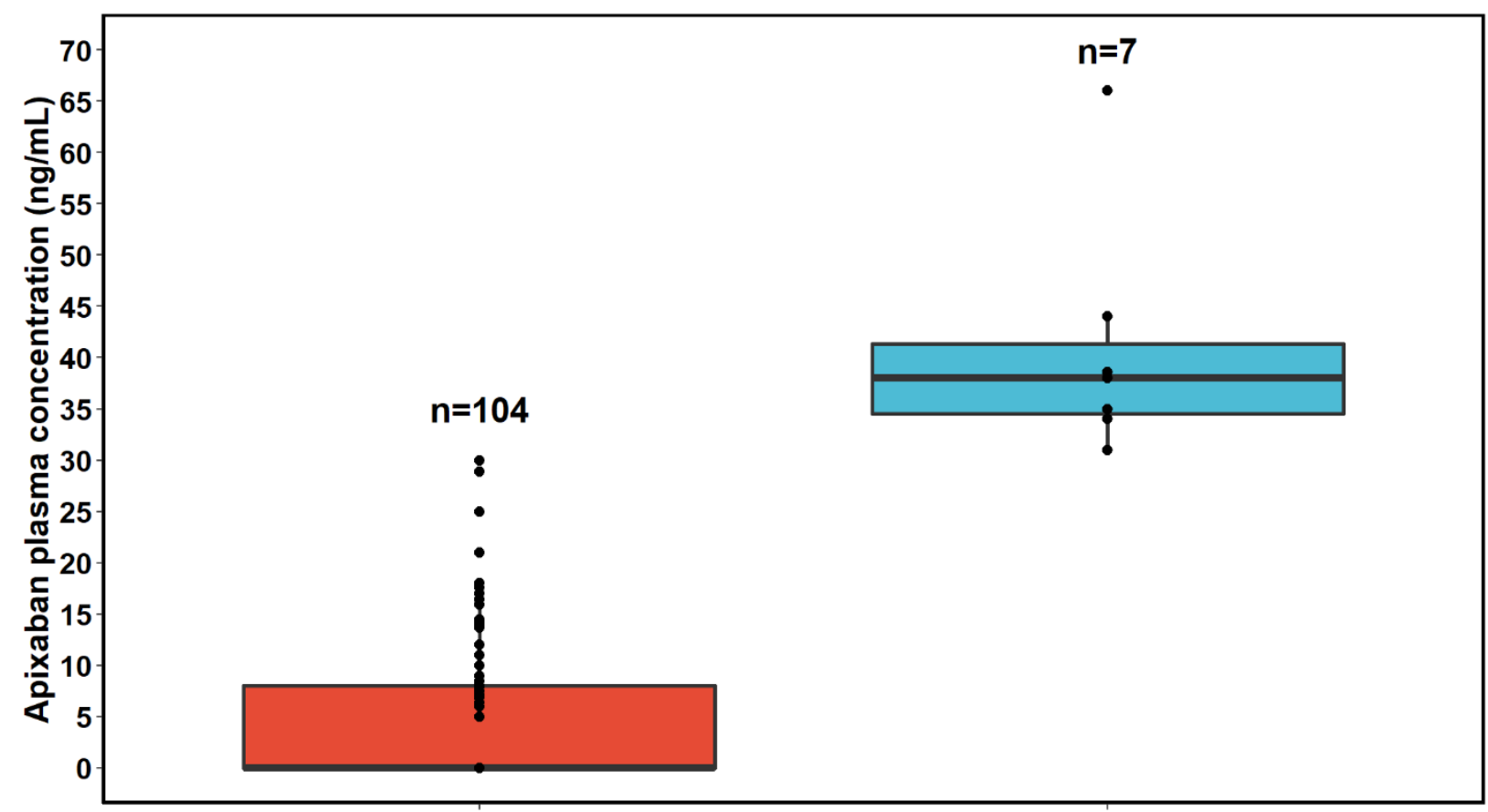


Figure 4. Proportion of patients who had apixaban concentrations $>30 \mathrm{ng} / \mathrm{mL}$ according to time since last dose.

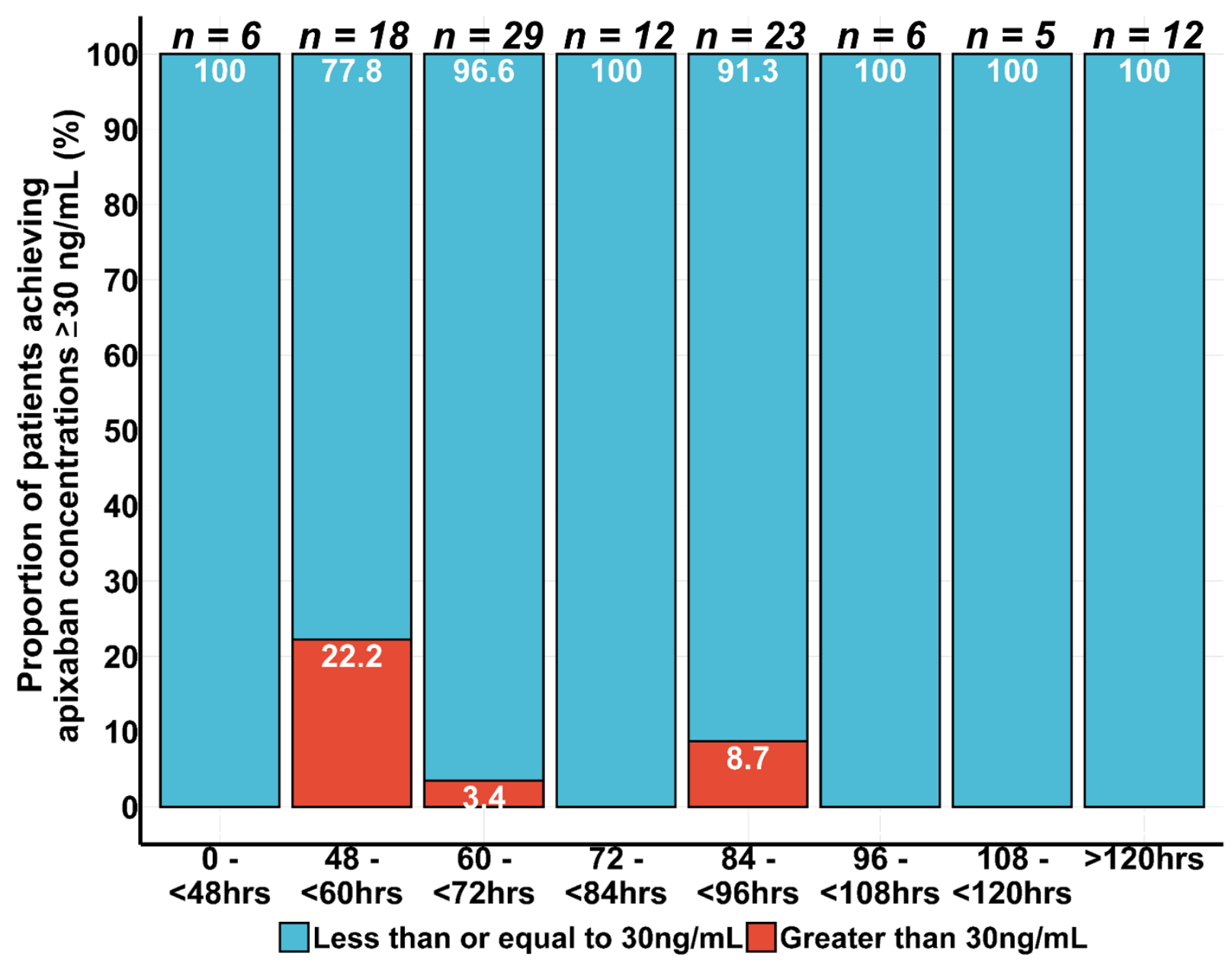


Figure 5. Apixaban concentration following discontinuation on the day of surgery grouped by dose

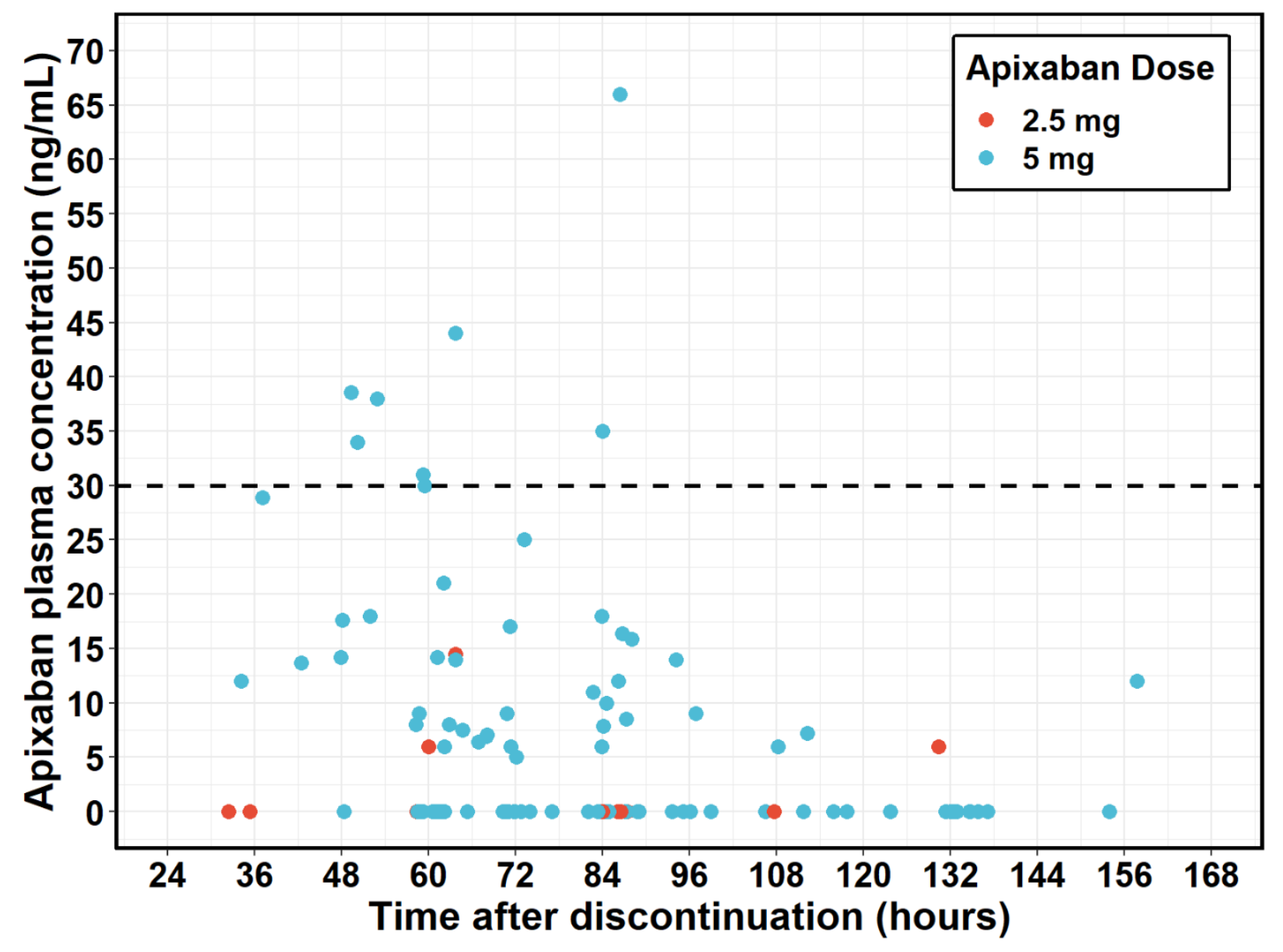


Supplemental Figure 1. Correlation between plasma apixaban concentration and apixaban antiXa activity

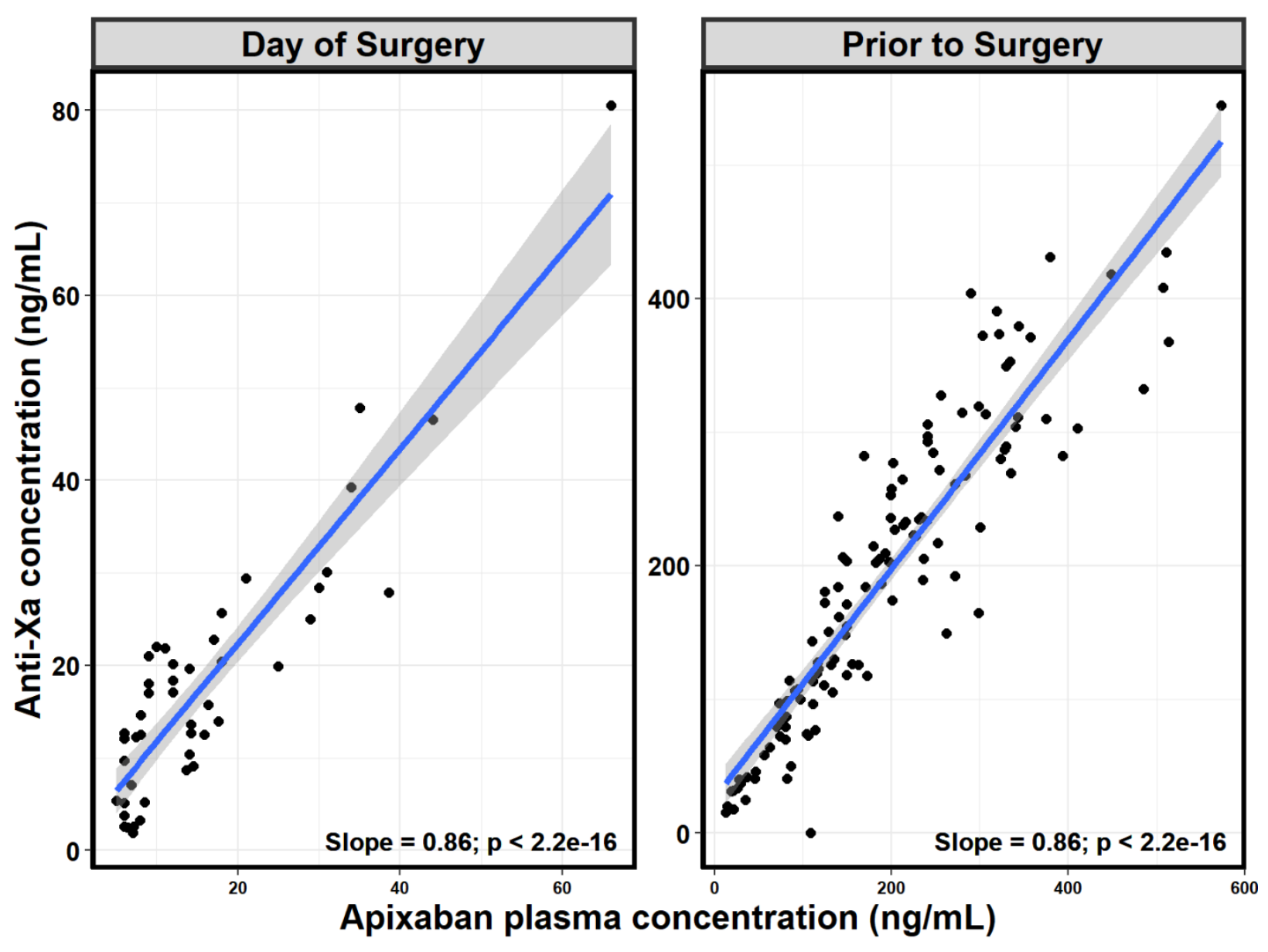


Supplemental Figure 2. Correlation between log plasma apixaban concentration and patient age, sex, weight and bleeding risk on the initial visit prior to surgery. Sex and risk are bounded by interquartile ranges.
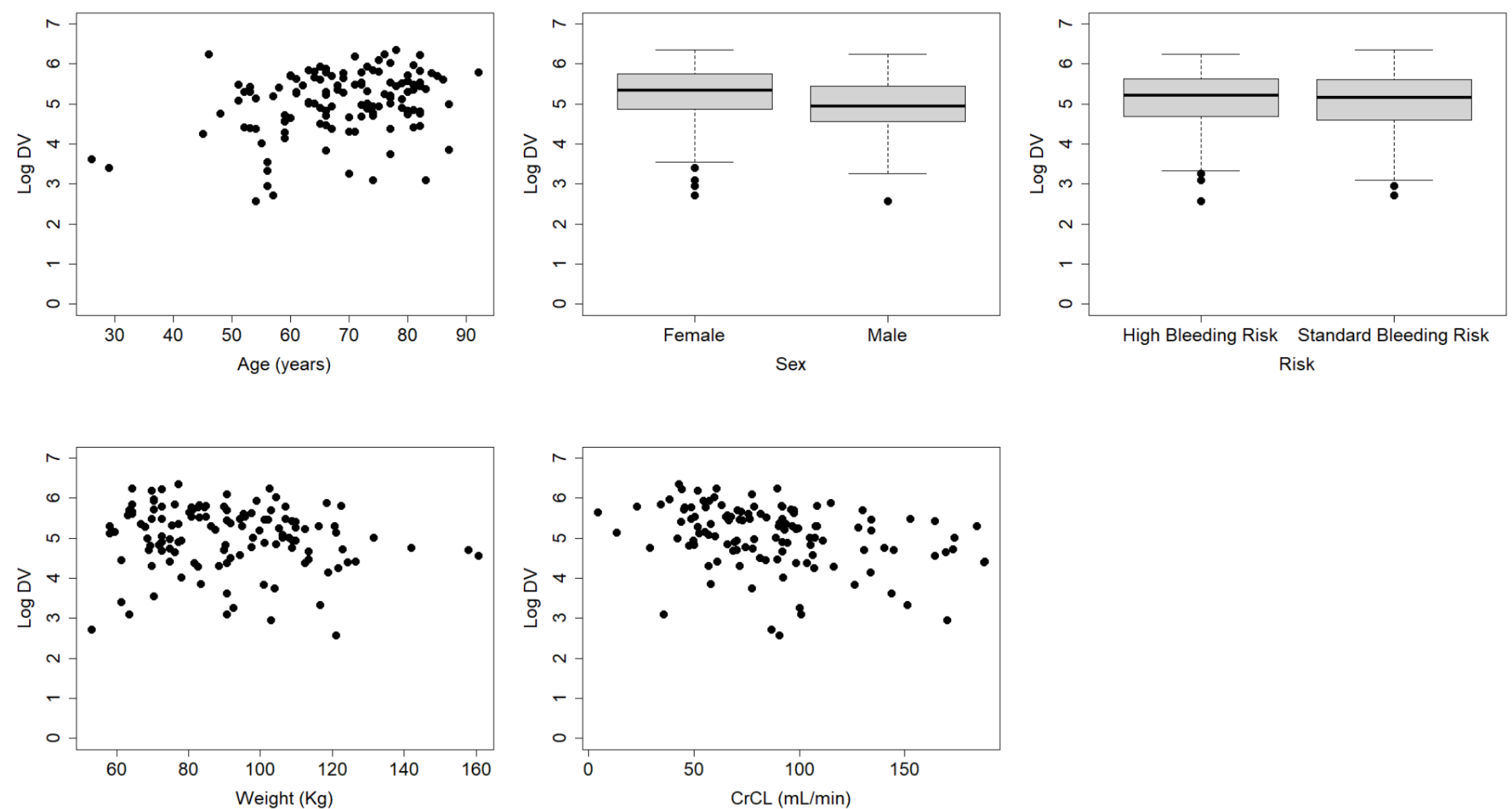
Supplemental Figure 3. Correlation between log plasma apixaban concentration and patient age, time after discontinuation, sex, bleeding risk, weight, and creatinine clearance on the day of surgery. Sex and risk are bounded by interquartile ranges.
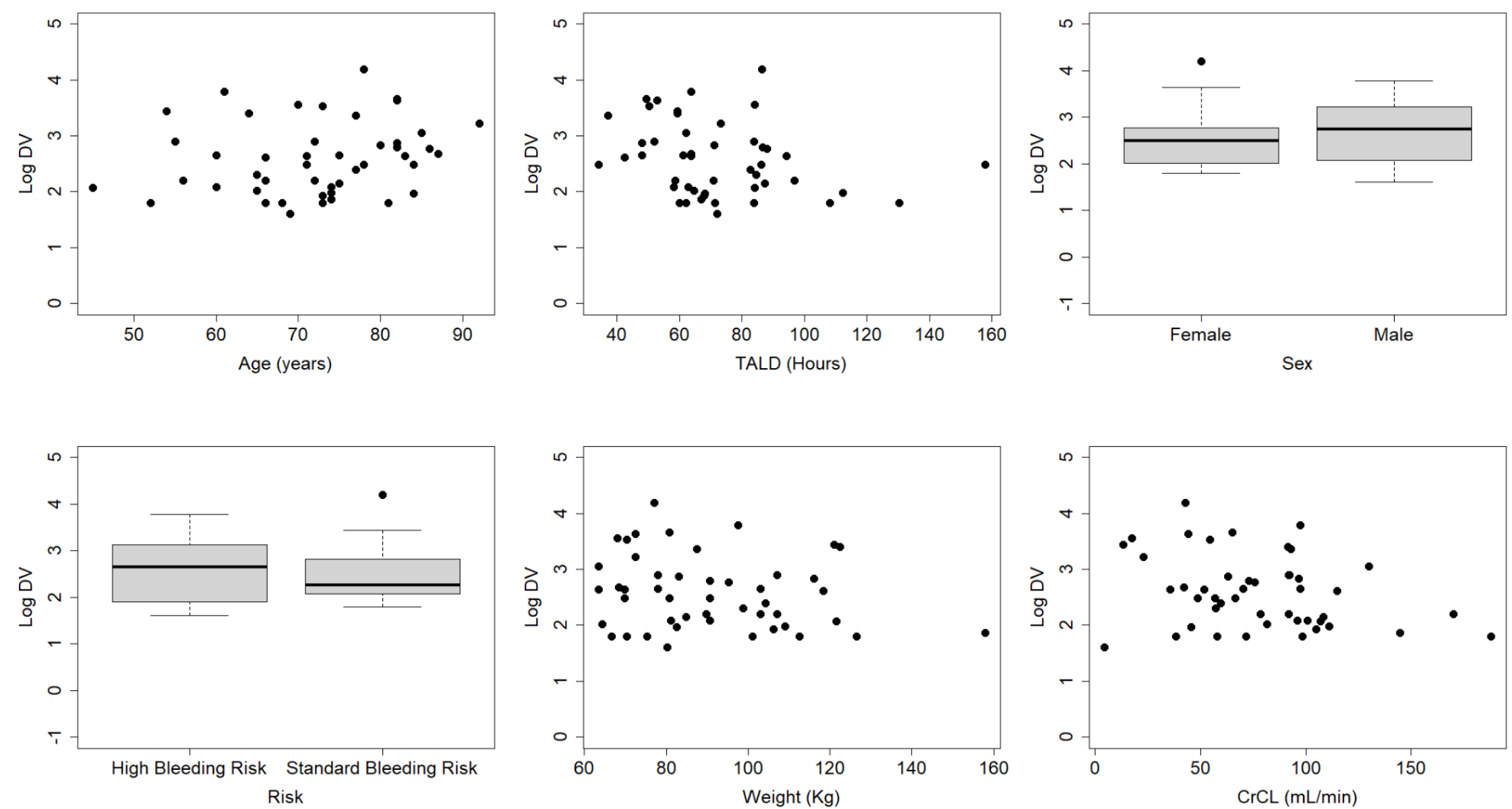
Supplemental Table 1. Surgical Procedures and Bleeding Risk

\begin{tabular}{l} 
High risk for bleeding \\
1. Major cardiac surgery \\
2. Neurosurgery \\
3. Large hernia repair \\
4. Major cancer surgery \\
5. Major urologic surgery (prostate/bladder resection) \\
6. Major vascular surgery \\
7. Any other major operation with duration $>45$ minutes \\
8. Endoscopic large polyp resection \\
9. Esophageal variceal treatment, biliary sphincterectomy pneumatic dilatation \\
10. CT-guided fine-needle aspiration; kidney biopsy \\
11. Pacemaker/ICD insertion \\
12. Major dental procedure (multiple extractions) \\
Standard risk for bleeding \\
1. Major orthopedic surgery (joint replacement or laminectomy) \\
2. Coronary angiography /PCI/electrophysiologic testing \\
3. Indwelling catheter for neuraxial anesthesia \\
4. Cholecystectomy, appendectomy (open or laparoscopic) \\
5. Abdominal hernia repair \\
6. Abdominal hysterectomy \\
7. GI endoscopy \pm biopsy, enteroscopy, biliary/pancreatic stent w/o sphincterotomy \\
\hline
\end{tabular}

Supplemental Table S2. Clopper-Pearson exact 95\% confidence of plausible observed sample proportions of those meeting the apixaban plasma level $\leq 30 \mathrm{ng} / \mathrm{dL}$ threshold after apixaban discontinuation 48 hours prior to major surgery or invasive procedures.

\begin{tabular}{|c|c|c|}
\hline $\begin{array}{c}\text { Observed proportion plasma } \\
\text { apixaban } \leq 30 \mathrm{ng} / \mathrm{mL}\end{array}$ & $\begin{array}{c}\text { 95\% Confidence } \\
\text { Interval }\end{array}$ & Interval Width \\
\hline 0.80 & $(0.72,0.87)$ & 0.15 \\
\hline 0.85 & $(0.78,0.91)$ & 0.13 \\
\hline 0.90 & $(0.84,0.95)$ & 0.11 \\
\hline 0.95 & $(0.90,0.98)$ & 0.08 \\
\hline 1.00 & $(0.97,1.00)$ & 0.03 \\
\hline
\end{tabular}

